\title{
Pocket Queens: Poker, Women, Stories
}

\author{
Julie Rak \\ This non-peer reviewed entry is published as part of the Critical Gambling Studies Blog. Visit an \\ interactive version of this blog at: https://criticalgamblingstudies.blogspot.com/2021/03/pocket- \\ queens-poker-women-stories.html
}

It's the dead of winter in Edmonton, and it's a cold, clear Friday night. Time to play some poker.

With my work day done, I turn off my computer, and I put on a pair of old jeans and a dark hoodie. I reserve my spot, and then get my gear together: my phone and earbuds, my money clip with the magnet for a couple of loonies, and my Humanities Special Achievement Medal from 1989. It's round and heavy, and has part of my undergrad university's crest on it. It's a perfect card marker because it's impossible to ship with the pot by accident, and it's the part of my academic identity that I can take along with me to the card room without saying too much about it. Into the money clip I put a wad of bills that's worth a couple of buy-ins (but I hope I only use one) with a bit of extra cash for some food. I put all this into my pockets with my keys, bank card and driver's license, and I'm ready to go. As I drive down the highway, I can see just a few stars twinkling in the night sky. Twilight comes early to my northern Canadian city in the winter. There is fresh snow on the ground, so I'm careful on the road. I feel the concerns of the day move away, and I clear my mind for the night ahead.

It's a busy night at my regular casino. During the height of the latest oil (and poker) boom, Edmonton, Alberta was one of the capitals of poker in North America, with more poker rooms than anywhere except Vegas and Atlantic City. At one point, there were at least six 24-hour rooms attached to casinos scattered around the city and on the Enoch Cree Nation reserve just outside the city limits. Now there might be four, which is still a lot for a city of 1.5 million people, and there are always rumours of more opening and some closing, some with big action and some small-stakes. Poker is not big business for Edmonton casinos: table games like Pai Gow or Blackjack make more money for the house, and slots make the most money of all. But like floor shows and buffets, poker is there to maintain a casino's image. You never know, some of those poker players might be waiting to get onto a poker table and go looking for easy money at slot machines like Wonder Woman or the ones with the big progressive jackpots. And, management figures, the friends and wives of poker players might come along for the ride and play a few slots themselves.

Wives. The little research there is on brick and mortar casino poker playing in North America estimates that few of the players are women: the percentage of women in the World Series of Poker Main Event, the best-known tournament in the world, was just 3.5\% in 2012 (Abarbanel and Bernhard). There are no statistics about queer players like myself, but I'm willing to bet that the number is even lower. It's evident who is in the majority as I walk through the parking lot filled with huge trucks paid for by the oil fields in the north, by the smoking area where I hear some guy say, 'I had a set! And he CALLED!' 


\section{Critical Gambling Studies Blog}

and then into the tired Western-style themed poker room with the buzzer security system that never actually works.

As I walk into the room, the noise hits me in the face, dozens of men talking at once, some shouting. I'm glad to see that there are six ring game tables and a tournament running. There's going to be lots of choice and I should find a profitable table easily. The players are almost all men, half of them white and half of them not, hunched over intently waiting for their cards, complaining to their friends about terrible hands they had, laughing at jokes, trying, and failing to get the waitress' attention, lining up at the wicket for chips. This is not Casino Royale. It's grubby and it's loud. There are three TVs blasting sports-hockey, curling and golf-and I can hear the jangle of the slots in the background. Dealers and house staff run about, managing the tournament. Someone is complaining about the fans running at top speed in the dead of winter. Lowell, a retired businessman who loves poker as much as he loves hunting is eating a steak and fries with gusto in the back lounge as he waits for a table. He is sporting an 'I Love Trump' button on his jacket. This is the kind of scene that made Victoria Coren leave the room the first few times she tried to play in a casino, but by now, I'm used to it (Coren, 2009, p. 32). I nod to a few of the regulars - Wanda (one of three female players in the room) with her hat decorated with rhinestones and a sparkling card marker in the shape of a toad; Cyril, the former naval officer and current department store Santa with big anchors tattooed on his forearms; Ngyen, a businessman always ready to joke, who owns a chain of sandwich shops; Lai, a quiet and methodical trans player who I see has invested recently in an excellent suit jacket and tie; and Viktor, an elderly birdwatcher with a handlebar mustache who lives in his van. I'll talk to them all later, when I'm settled in.

Across the room, I see Bill, the trout fly designer and Frida, one of the best women players in Edmonton and a former dealer, playing for high stakes at the Omaha game with young, eager men who are laughing, shouting, and not paying enough attention to the pros at the table. As the night wears on, those big chip stacks in front of them could dwindle to nothing. Or, if Frida and Bill are unlucky, those stacks could grow even larger, at their expense. That game is too rich for my blood, I think for the hundredth time.

I check in with the houseman who manages the room and get seated right away. I throw down my card marker to mark my seat, and notice that most of the men do not look very happy to see me, probably for several reasons. I'm used to this. The players who know me are disappointed not to see an easy mark. Others see only a middle-aged white woman and feel that I'm intruding on their masculine turf, or that I am not the eye-candy they would rather see. A couple of guys think it's only a woman and assume that I'll be a passive, substandard player. Others just don't care: they are thinking only about their chip stack and their cards. But the dealer smiles: it's Tran, one of my favourites. Tran was a doctor back home but can't get certified here. We have a lot of respect for each other. I buy chips at the wicket, put them down at my spot and then I go to the back and get some soda water and ice.

I'm ready to play. 
This blog post has an argument to make about women in poker, but to do that it begins a little differently from what some researchers in the field of gambling studies might be used to seeing. I began with a story of my own to show that poker players do have their own stories to tell, stories that could tell researchers a lot about the culture of poker and its politics in the twenty-first century. As a woman, I am part of a minority in poker, long considered a man's game and a sign of hypermasculinity, even now (Palomäki et al., 2016). I encounter sexism in poker, and homophobia too, every time I play, in complex ways connected to race and class issues, among other inequities and alliances in poker's practices. Therefore I think that my experiences, and the experiences of other women, including trans women, Indigenous women and women of colour, deserve respect. There are some studies that have identified everyday sexism in poker where women strategize within and against assumptions about them as players, in what is often an aggressively macho world (Abarbanel \& Bernhard, 2012), strategies that often do not challenge gendered or heterosexist hierarchies (Wolkomir, 2012). Such studies are based on ethnographic and interview work. But what of the stories that players, especially female and other minority players, have to tell in their own terms? Here is where poker research could go if poker is assumed to have cultures and histories. In that light, methods from the humanities about stories and representation could have much to add to the field of critical gambling studies, because poker is a game of and for representation in first person accounts, and in other aspects of autobiographical discourse. A focus on autobiographical stories can help to highlight who players are, and what their everyday lives as players are like when they are not being studied by experts. As Sidonie Smith and Julia Watson have pointed out, autobiographical stories (called life writing, which includes other forms like diaries or biographies) serve many cultural functions, including the work of testimony, the work of narrative in creating the writing subject as they assemble and rework the stories of their lives, and the ethics of telling life stories that would otherwise be forgotten or discounted. Such stories are creative, and yet based on truth claims. They compel their readerships and inspire them, as they instruct and entertain, sometimes all at once (Smith \& Watson, 2010, pp. 31-63). In the last twenty years, the work of life writing has become part of the methodology of cultural studies, as it unites the action of social forces on individuals with the everyday lives of people who are not merely captive to hegemonic ideology. Life writing itself, within autoethnography and more broadly in cultural studies has become an important way to understand how experience, in the words of Joan Scott, is both an interpretation and in need of an interpretation (Scott, 1991, p. 797).

Using life writing to focus on the culture of poker means that methods and theory from the humanities and the social sciences can be used in order to respond to Fiona Nicoll's pithy observation that 'researchers need to expand their methods beyond the survey and the laboratory to spend more time playing and talking with gamblers' (Nicoll, 2019). Actually talking with and even playing with poker players could shed light on the gender, class and race politics of poker itself, and can help researchers respect poker as cultural work rather than regard it as a pathology. What Nicoll calls the trope of the problem gambler is not based very often on the experiences or the voices of players in casino environments, and there is more than a little moral high-ground assumed by some researchers about those they research, because presumably they are not the 'problem' they think about. James Cosgrave in a blog post supporting critical gambling studies in social theory points out the problems with the focus on individual as problem in problem gambling research, observing that 'problem gambling research is not gambling studies. It is rather an extension or application of addiction 
research to gambling' (Cosgrave, 2020). But he goes on to say significantly that simply focusing on the social work of gambling may also make the gambler as an agent disappear as well.

The voices of female poker players, then, have more than one way to be easily lost. Here is an example of how this can happen: for example, in this particular study, it is assumed that 'poker players are at high risk of experiencing gambling problems. Despite the feminization of gambling, little is known about the problems associated with poker playing among women' (Morvannou et al., 2020). The study proceeds from female poker players as problematic, not from their experience as players. It is important, of course, to study problem gambling and I do not mean to say that there are no problem gamblers who play poker. But the authors proceed from the idea that women who play poker are only seen when they are a 'problem' for research.

Michel Foucault pointed out a similar attraction to pathology as a field-generating activity in the study of deviance and sexuality in the nineteenth century. Psychiatry and medicine developed as sciences by overcoming initial revulsion at the subject matter. 'How could a discourse based on reason speak of that?' Foucault asks rhetorically, connecting the need for the new areas of research to turn their attention to thinking about, and then medicalizing, the study of sex (Foucault, 1978, p. 24). The key for Foucault is the turn from sex to discourse and where experts strive to set their revulsion aside, which is what made it possible to study it. He says of this strategy:

What is essential [in this professional desire to overcome revulsion] is not in all these scruples, in the 'moralism' they betray, or in the hypocrisy one can suspect them of, but in the recognized necessity of overcoming this hesitation. One had to speak of sex; one had to speak publicly and in a manner that was not determined by the division between licit and illicit... one had to speak of it as of a thing to be not simply condemned or tolerated but managed. (Foucault, 1978, p. 24)

Proceeding with research from the figure of the problem gambler, and then creating an understanding of gender which simply says female poker players are problem players too, is a way to consolidate a research field and manage its subjects as problems for the field. One must speak of that, which is poker, and of them, women who play, as the illicit, while the researchers create the idea of the licit, in the name of the management of pathology.

The study of poker, therefore, is not well served by being just another field for research into problem gambling. By the same token, the few studies there are of female players do not, as a rule, feature the voices of those players. There are relatively few accounts in the literature of their experiences and motivations.

And so, if poker has a culture, what is that culture like, beyond the categories of recreational gaming and problem gambling? And more specifically, what is poker like for all women who play? The stories women themselves must tell could be a good place to start. Here I am thinking of the possibilities of studying the autobiography and biography of many kinds of female players, from those who write memoirs about their time on the World Poker Tour as Victoria Coren has done in For Richer, For Poorer (Coren, 2009), those who are part of the star system which has developed since the advent of televised tournaments and online sites as Annie Duke has done in her own memoir of the game (Duke \& Diamond, 2005), to online autobiographical and biographical forms-including blogs_of figures like Vanessa Selbst, Jennifer Harman or even 'Poker Alice', Alice Duffield Tubbs, the unforgettable 
impresario, player and dealer from the early American west who appears in James McManus' Cowboys Full: the Story of Poker (McManus, 2009, pp. 172-176). All these stories matter, and can work against the tendency in the popular press to focus on the glamour of female players' lives, ignoring the gender politics they talk about. Their stories are only part of the picture: there are also stories of other relatively ordinary players, who raise, call and fold far from the World Series of Poker and the lights of Monte Carlo, Macau or Las Vegas.

I usually play for about 6 hours, and I can feel that it's getting late. I look at my watch-it's 1:00 am. The tables are getting quiet and things are settling down. I used to be able to play all night and would sometimes do this if I were down chips, but I have learned that the more tired I get, and as winning players leave the game, it's just not worth it unless the game is unusually lucrative. I have had a good time, anyway, catching up with some of my friends, laughing at Cyril's awful off-colour jokes, and winning some pots. I'm ahead by a good margin. I have about an hour before I really have to leave, and I might leave earlier because there's a guy who clearly thinks he's fantastic in seat one. He makes big raises and forces people out of pots. He's not all that good, although it isn't the worst strategy, because he plays every hand and he would never win them all any other way. He has been scooping a lot of pots, plus getting lucky on a few. He has about $\$ 1500$ in front of him, which is a lot for the small Hold 'Em game we are playing, and the guys near me are starting to grumble and look at him hungrily. I look at him too for a bit. He's white, heavy-set and wearing a hockey jersey, and he's been talking loudly about hockey as he drinks beer after beer, sitting next to Alan (the father of an NHL player) who is very patiently waiting for the guy to make a mistake. I re-raised the guy in the last hand when I was holding an Ace and a King, and he folded, loudly saying, 'Next time little lady, it's not going to be so easy for you.'

Little lady? Vin, the player next to me, starts laughing silently because he knows what I'm thinking. 'What are you going to do about that?', his look says. I know that this is my weak spot because I hate it when guys are patronizing. I have made some money tonight, but if I stay, I could end up donating to this guy, and I don't want to do that. There's nothing worse than donating chips to some sexist jerk as he laughs in your face. One more hand, I think. I look down at the two cards I'm dealt, and it's QQ. Pocket Queens, the Ladies. Now this is a hand. It's going to be great or it's going to hurt. But I'm last to act. The guy in seat 1 is first, and he opens his eyes in surprise, and he raises to $\$ 100$. He literally could have anything, and I have $\$ 800$ in front of me. He's got me covered. It's a good gamble, maybe. I take out my ear buds. I decide to re-raise to $\$ 300$. In an exaggerated movement, with a wink at the guys beside him, he shoves at his chips, yelling all-in. Alan just sits there, willing me to fold. Everyone thinks I'm going to fold. The guy even says I'll fold too, in a satisfied way. 'You can't call that,' he says.

And me? I've got $\$ 400$ left and that's a lot to risk after playing for a few hours. Frida wouldn't even blink an eye, but it's hard for me. I probably have him beat, although that move could be because the guy has AA or KK (two Aces or two Kings) and then it's over. I have had it happen before. This is where

DOI: https://doi.org/10.29173/cgs100 
most female players are supposed to fold. And should I? I can see the same hockey highlight on the TV that I saw 2 hours ago. I'm sick of being here now and I want to go home. I go over in my mind everything the guy said and did for the last 4 hours.

The guy asks the dealer to give him the chips because he's tired of waiting and I say, 'No, you've got to wait. Just because I'm a little lady doesn't mean I don't get to think with my little brain.' Somebody laughs. But I already know what I'm going to do. I shove in all my chips, as the table sucks in its collective breath.

The guy turns over an awful hand, K10 (King 10) suited. It's annoying because it's such a bad hand, and also terrifying. What if a King hits and my pair is gone, or what if he gets a straight or flush? One King does appear, and I think it's over for me, but the next card is a Queen. I win with trips, as the guy chastises me for staying in the hand and tries to defend himself from Johnny the pipe fitter in seat four, who is trying to make him understand that his play didn't make sense. Other players congratulate me, I stack my chips, and Tran, my dealer, gives me a little smile as I shoot him a generous tip. The guy rearranges his shrunken chip stack and asks me, in a wounded voice, why I called him on such a big bet.

'I just love the Ladies,' I say. And I smile just a little bit.

And then I get chip racks, fill them up, put on my jacket, pick up my card marker, cash out and walk away from poker into the clear, cold dark of an early Saturday morning.

Julie Rak is H.M. Tory Chair in the Department of English and Film Studies at the University of Alberta, Canada. Her latest book is False Summit: Gender in Mountaineering Nonfiction (McGill-Queens UP, 2021).

\section{References}

Abarbanel, B. L., \& Bernhard, B. J. (2012). Chicks with decks: The female lived experience in poker. International Gambling Studies, 12(3), 367-385. https://doi.org/10.1080/14459795.2012.680900

Coren, V. (2009). For Richer, For Poorer: Confessions of a Player. Canongate.

Cosgrave, J. (2020). Gambling and Social Theory_Part 1. Critical Gambling Studies. https://doi.org/10.29173/cgs56

Duke, A., \& Diamond, D. (2005). How I Raised, Folded, Bluffed, Flirted, Cursed, and Won Millions. Hudson Street Press.

Foucault, M. (1978). History of Sexuality: An Introduction (R. Hurley, Trans.; Vol. 1). Random House. McManus, J. (2009). Cowboys Full: The Story of Poker. Picador. 


\section{Critical Gambling Studies Blog}

Morvannou, A., Kairouz, S., Andronicos, M., Jobin, E., Berbiche, D., \& Dufour, M. (2020). Poker playing among women: Understanding factors associated with gambling problems. Journal of Gambling Issues, 45/46, 1-20. https://doi.org/10.4309/jgi.2020.45.2

Nicoll, F. J. (2019). Gambling in everyday life: Spaces, moments and products of enjoyment /. Routledge.

Palomäki, J., Yan, J., Modic, D., \& Laakasuo, M. (2016). "To Bluff like a Man or Fold like a Girl?" - Gender Biased Deceptive Behavior in Online Poker. PLoS ONE, 11(7), 1-13.

https://doi.org/10.1371/journal.pone.0157838

Scott, J. W. (1991). The Evidence of Experience. Critical Inquiry, 17(4), 773-797.

Smith, S., \& Watson, J. (2010). Reading Autobiography: A Guide for Interpreting Life Narratives. University of Minnesota Press.

Wolkomir, M. (2012). "You Fold Like a Little Girl:" (Hetero)Gender Framing and Competitive Strategies of Men and Women in No Limit Texas Hold Em Poker Games. Qualitative Sociology, 35(4), 407-426. https://doi.org/10.1007/s11133-012-9235-3 